\title{
Inhibition of bovine fertilization in vitro by antibodies to SP-10
}

\author{
S. A. Coonrod ${ }^{1 *}$, J. C. Herr ${ }^{2 \dagger}$ and M. E. Westhusin ${ }^{1}$ \\ ${ }^{1}$ Department of Veterinary Physiology and Pharmacology, Texas A\&M University, College Station, \\ TX 77843, USA; and ${ }^{2}$ Center for Recombinant Gamete Contraceptive Vaccinogens and the Department \\ of Cell Biology, University of Virginia, Charlottesville, VA 22908, USA
}

\begin{abstract}
The inhibiting effect on fertilization of antibodies to the intra-acrosomal protein SP-10 was studied in a bovine in vitro fertilization model. Indirect immunofluorescence showed that antibodies to human SP-10 localized to the acrosomal region of methanol-fixed, but not live, bovine spermatozoa, confirming the intra-acrosomal localization of bovine SP-10. The presence of the SP-10 protein in bovine spermatozoa was further established by immunoblotting of extracts of bovine spermatozoa with monoclonal antibodies and polyclonal antibodies to human SP-10. The antibodies identified a pattern of immunoreactive peptides similar to human, baboon, monkey and pig SP-10. Fertilization experiments in vitro demonstrated that monoclonal antibodies, as well as polyclonal antibodies, to human SP-10 significantly reduced fertilization rates of bovine oocytes by bovine spermatozoa. SP-10 antibodies exerted their anti-fertilization effect by reducing sperm-zona secondary binding. Consistent with the accessibility of the SP-10 antigen following capacitation, SP-10 antibodies also reduced the ability of capacitated spermatozoa to complete the acrosome reaction. Furthermore, SP-10 antibodies affected the motility of capacitated spermatozoa, while not affecting the motility of noncapacitated spermatozoa.
\end{abstract}

\section{Introduction}

SP-10 is an intra-acrosomal protein known to be conserved across various mammalian species including humans, baboons, macaques, pigs, foxes and mice (Freemerman et al., 1994; Reddi et al., 1995). Western blots of extracts of human, baboon and macaque spermatozoa using MHS-10, a monoclonal antibody to $S P-10$, revealed that the acrosome contains a series of immunoreactive SP-10 proteins with molecular masses in the range 18-34 kDa (Herr et al., 1990a, b). This microheterogeneity of human SP-10 is not affected by the presence of protease inhibitors (Herr et al., 1992) and the immunoreactive pattern of human SP-10 changes little throughout sperm maturation (Foster et al, 1994). N-terminal microsequences derived from purified native (Herr et al., 1992), as well as recombinant (Reddi et al., 1994), SP-10 peptides have been compared with the amino acid sequence deduced from SP-10 cDNAs (Wright et al., 1990), and the immunoreactive SP-10 peptides were shown to be derived from a common precursor protein (Herr ef al., 1992). In mature human spermatozoa, as well as in developing spermatids, SP-10 is localized within the acrosomal matrix and is also associated with the acrosomal membranes (Herr et al., 1990b; Kurth et al., 1991; Foster and Herr, 1992). After the acrosome reaction SP-10 remains associated with the inner acrosomal membrane and equatorial segment (Herr et al., 1990b, Foster et al., 1994).

\footnotetext{
*Current address: Center for Recombinant Gamete Contraceptive Vaccinogens and the Department of Cell Biology, University of Virginia, Box 439, Charlottesville, VA 22908, USA.

†Correspondence.

Received 26 January 1996
}

The World Health Organization Taskforce on Contraceptive Vaccines designated SP-10 a 'primary vaccine candidate' because of its tissue specificity and evidence that the MHS-10 monoclonal antibody inhibits the penetration of zona-free hamster eggs by human spermatozoa (Anderson et al., 1987). In addition, a monoclonal antibody that recognizes an antigen considered to be SP-10 inhibited in vitro fertilization (IVF) by blocking sperm attachment to and penetration of the zona pellucida in mice, pigs and humans (Dubova-Mihailova et al., 1991). Recently, a monoclonal antibody that recognizes a human intra-acrosomal antigen, displaying similar characteristics to SP-10, was shown to inhibit the penetration of zona-free hamster ova by human spermatozoa (Jimenez et al., 1994). However, despite these indications that antibodies to SP-10 inhibit IVF, the precise stage in the events of fertilization at which antibodies to SP-10 exert their effects is unknown.

In the present study, bovine SP-10 was immunochemically and histochemically defined. Using the bovine IVF model, previous reports that antibodies to SP-10 reduce fertilization rates in vitro were confirmed. Bovine gametes were used for these experiments because large numbers of oocytes can be obtained at a low cost from abattoirs and fertile bull spermatozoa can be collected and frozen, thus yielding a standardized source of spermatozoa. In an attempt to learn more about the functional properties of the SP-10 protein, the bovine model was used to investigate the stage in the fertilization process at which antibodies to SP-10 exert their effect. Results show that antibodies to SP-10 reduce tight binding of spermatozoa to the zona, the percentage of spermatozoa completing the acrosome reaction and sperm motility. 


\section{Materials and Methods}

\section{Preparation of antibody and protein}

The creation of the MHS-10 hybridoma and the production of the monoclonal antibody (mAb) to MHS-10 were as described by Herr et al. (1990b). The 6C12 and 3C12 monoclonal antibodies were generated by the method of Chapman et al. (1984) against a recombinant human SP-10 fusion protein consisting of amino acids 57-181 fused to glutathione transferase (Herr et al., 1994). Rabbit polyclonal antisera were generated against a recombinant fusion protein in which amino acids 4-214 of human SP-10 were fused to $\beta$-galactosidase and the sera was processed for isolation of IgG by ammonium sulfate precipitation (Wright et al., 1990).

The control (null ascites) for the SP-10 mAbs ascites was a pristane-induced clarified mouse myeloma ascites (Organon Teknika, Durham, NC) of the same class (IgG) as the SP-10 $\mathrm{mAbs}$. The protein concentration for the control ascites was $52 \mathrm{mg} \mathrm{ml}^{-1}$, while the protein concentration for the monoclonal antibody ascites ranged from 43 to $55 \mathrm{mg} \mathrm{ml}^{-1}$. The control for the polyclonal antibody was an IgG preparation of rabbit pre-immune sera. Protein concentrations were determined by the method of Bradford (1976).

\section{Gamete preparations}

Bovine spermatozoa and ova were collected and prepared as described by Coonrod et al. (1994).

\section{Immunofluorescence microscopy}

Frozen-thawed bovine semen samples were washed three times by centrifugation at $650 \mathrm{~g}$ for $5 \mathrm{~min}$ in PBS and fixed for $30 \mathrm{~min}$ in methanol as described by Coonrod et al. (1994). Non-specific binding sites were blocked for 30 min using PBS containing $5 \%(\mathrm{w} / \mathrm{v}) \mathrm{BSA}$ and preparations were placed in a humidified air chamber and incubated at a 1:30 dilution with either SP-10 specific antibodies or control antibodies overnight at $5^{\circ} \mathrm{C}$. Samples of motile spermatozoa were obtained from frozen-thawed, Percoll-washed bovine semen and incubated in spermatozoa TL (Sp-TALP; Parrish et al., 1988) containing a 1:30 dilution of rabbit polyclonal antibody to human SP-10 or pre-immune sera for $2 \mathrm{~h}$ at room temperature. After incubation, approximately $85 \%$ of the spermatozoa were motile. Sperm samples were washed three times by centrifugation at $650 \mathrm{~g}$ for $5 \mathrm{~min}$ and air-dried on microscope slides. Antibody-binding sites for both methanol-fixed and live spermatozoa were localized using a 1:50 dilution of fluorescein isothiocyanatelabelled goat anti-mouse or goat anti-rabbit immunoglobulins (Sigma, St Louis, MO) for $2 \mathrm{~h}$ at room temperature (Coonrod et al., 1994). Slides were then gently washed for $5 \mathrm{~min}$ with PBS and coverslips in a glycerol mounting media containing an anti-fade reagent (Slow Fade; Molecular Probes, Eugene, OR were added). Sperm preparations were examined for fluorescence using an epifluorescent microscope (Zeiss, New York) equipped with a mercury lamp using a $490 \mathrm{~nm}$ excitation filter and $525 \mathrm{~nm}$ barrier filter.

\section{Western blot analysis}

Frozen-thawed bovine semen samples were washed three times by centrifugation at $650 \mathrm{~g}$ for $5 \mathrm{~min}$ in PBS and the pellets were frozen at $-20^{\circ} \mathrm{C}$ in PBS until use. Sperm samples were thawed and membranes disrupted by sonication. After centrifugation, the pellet was discarded and the protein concentration of the supernatant was determined (Bradford, 1976). Protein preparations $(50 \mu \mathrm{g})$ were mixed with sample buffer $\left(1 \% \operatorname{SDS}(\mathrm{w} / \mathrm{v}), 0.03 \mathrm{~mol}\right.$ Tris $l^{-1}, 0.5 \%$ glycerol $(\mathrm{v} / \mathrm{v}), 0.25 \%$ $\beta$-mercaptoethanol $(w / v)$ and $0.005 \%$ bromophenol blue $(w / v))$, boiled for $5 \mathrm{~min}$ and separated under reducing conditions on one-dimensional $12 \%$ slab SDS-PAGE minigels (Mini-Protean II; Bio-Rad, Bedford, MA; Laemmli, 1970). For non-denaturing and non-reducing gels (native) $\beta$-mercaptoethanol and SDS were not added to the sample buffer, the samples were not boiled, and SDS was not included in the electrophoresis buffer. After electrophoresis, proteins were electroblotted onto nitrocellulose membranes (Towbin et al., 1979). The immunoreactivity of all SP-10 antibodies and their controls was evaluated on blots from the same electrophoretic gel. Antigens were identified by overnight incubation at $5^{\circ} \mathrm{C}$ of the milkblocked nitrocellulose membranes with a $1: 100$ dilution of either SP-10 specific antibodies or control antibodies. The blot was then incubated for $2 \mathrm{~h}$ with either goat anti-mouse or goat anti-rabbit IgG-alkaline phosphatase (Sigma, St Louis, MO), for monoclonal antibody or rabbit polyclonal antibody, respectively. After each step in the western blot procedure, the membranes were washed three times with $10 \mathrm{mmol}$ Trissaline $\mathrm{I}^{-1}(\mathrm{pH}$ 7.2) for $\mathrm{I} \mathrm{h}$. Immunoreactive proteins were visualized using nitro-blue tetrazolium and 5-bromo-4-chloro3-indolyl phosphate as a substrate ( $\mathrm{Naz}$ et al., 1991).

\section{Absorption of antisera}

A precipitation assay (Hudson and Hay, 1983) was performed to determine the optimal concentration of recombinant baboon (rb)SP-10 for absorption of the MHS-10 monoclonal antibody. The rbSP-10 was added to Eppendorf tubes at increasing concentrations $(0,10,20,50,100$ and $200 \mu \mathrm{g}$ ) followed by the addition of a constant volume of MHS-10 ascites $(100 \mu \mathrm{l})$. Cold PBS was then added, giving each tube a final volume of $500 \mu \mathrm{l}$. After $1 \mathrm{~h}$ at $4^{\circ} \mathrm{C}$, the tubes were centrifuged for $5 \mathrm{~min}$ at $3000 \mathrm{~g}$ and the supernatant was discarded. The precipitate was then washed twice by centrifugation $(3000 \mathrm{~g}$ for $5 \mathrm{~min})$ with $\mathrm{PBS}$, redissolved in $0.1 \mathrm{~mol} \mathrm{NaOH} \mathrm{l})^{-1}$ and the protein concentration determined (Bradford, 1976).

\section{In Vitro fertilization trials}

For all IVF experiments the matured oocytes were washed three times in HEPES-buffered Tyrode's medium (low bicarbonate-TALP; Parrish et al., 1988) and vortexed for $10 \mathrm{~min}$ to disrupt and remove cumulus cells. The eggs (30-35 per well) were then transferred to $500 \mu \mathrm{l}$ aliquots of fertilization medium (Fert-TALP; Parrish et al, 1988) containing $10 \mu \mathrm{g}$ heparin $\mathrm{ml}^{-1}$ and SP-10 specific antibodies, control antibodies, or no antibodies. Frozen-thawed bovine spermatozoa were then 
centrifuged $(700 \mathrm{~g}$ for $30 \mathrm{~min})$ through a sperm-TL buffered Percoll gradient and the motile fraction added to the wells at $5.0 \times 10^{5}$ spermatozoa $\mathrm{ml}^{-1}$, followed by culture for $18 \mathrm{~h}$ at $39^{\circ} \mathrm{C}$ in a humidified atmosphere containing $5 \% \mathrm{CO}_{2}$ (Westhusin et al., 1992).

Heparin has been shown to induce the acrosome reaction in hamster (Handrow et al., 1986) and rabbit (Lenz et al., 1983) spermatozoa while apparently not affecting capacitation in these species. In contrast, in bovine spermatozoa, a $4 \mathrm{~h}$ incubation period with heparin (or other glycosaminoglycans) is essential for capacitation, while prolonged exposure to heparin results in a spontaneous acrosome reaction (Handrow et al., 1982). Before the heparin-induced capacitation period, spermatozoa are incapable of fertilization (Parrish et al., 1988). Therefore, preincubation of bovine spermatozoa with antiSP-10 antibodies before oocyte coculture was not considered necessary.

Fertilization rates were determined by fixing the oocytes $18 \mathrm{~h}$ after fertilization with an acetic acid-alcohol solution (I:3) for at least $12 \mathrm{~h}$, followed by staining with a $1 \%(\mathrm{w} / \mathrm{v})$ aceto-orcein solution and observing oocytes for pronuclear development under a dissecting microscope. Oocytes were designated 'unfertilized' if they contained a metaphase II plate or one pronucleus. Oocytes containing two pronuclei or that were polyspermic were considered 'fertilized' (Coonrod et al., 1994).

In the first experimental paradigm, the effect of SP-10 monoclonal antibodies (containing equal volumes of MHS-10, $6 \mathrm{C} 12$ and 3C12 monoclonal antibody ascites) on fertilization rates was tested at dilutions of 1:40, 1:20 and 1:10. A group containing a 1:10 dilution of null ascites and a group lacking antibodies served as controls for this experiment.

Next, the effect on the fertilization rate of the MHS-10 monoclonal antibody alone was tested. One control for this experiment was a group incubated in a 1:10 dilution of MHS-10 absorbed ascites. To absorb the MHS-10 monoclonal antibody, $100 \mu \mathrm{g}$ rbSP-10 was mixed with $450 \mu \mathrm{l}$ fertilization medium in a sterile Eppendorf tube followed by the addition of $50 \mu \mathrm{l}$ MHS-10 ascites. The supernatant was removed after incubation for $1 \mathrm{~h}$ at $5^{\circ} \mathrm{C}$ and added to the well. The main experimental group contained a $1: 10$ dilution of unabsorbed MHS-10 ascites. A third and fourth control group contained either 1:10 dilution of null ascites or no antibodies.

A third experiment used rabbit polyclonal antibodies to human SP-10. The polyclonal antibodies to SP-10 were tested at dilutions of 1:40, 1:20 and 1:10 with rabbit pre-immune sera serving as the principal control.

\section{Sperm-zona binding assay}

The SP-10 monoclonal antibody cocktail and null ascites were used in the sperm-zona binding assay at a 1:10 dilution. IVF was performed as described above. However, $17 \mathrm{~h}$ after fertilization, Hoechst $33342\left(100 \mu \mathrm{g} \mathrm{m}^{-1}\right)$ was added to the fertilization medium for $30 \mathrm{~min}$ at $37^{\circ} \mathrm{C}$ to stain spermatozoa fluorescently for quantitative analysis. Oocytes from the SP-10 monoclonal antibody group were randomly allotted into three groups of ten and gently transferred to dishes containing $5 \mathrm{ml}$ low bicarbonate-TALP which diluted the Hoechst to eliminate background fluorescence. The first group of eggs was placed in a glass depression slide and the number of spermatozoa bound to each zona was counted using an inverted microscope equipped with an argon laser ultraviolet light source (Zeiss, New York). Eggs from the second group were vigorously pipetted five times to remove loosely bound spermatozoa and the number of spermatozoa bound to each zona was again counted. Eggs from the final group were vortexed for $3 \mathrm{~min}$ and the number of spermatozoa that remained firmly attached to the zona pellucida, embedded within the zona, or had penetrated through the zona into the perivitelline space were counted. Oocytes from the null ascites group were then processed as the SP-10 monoclonal antibody group.

\section{Analysis of spermatozoa motility}

The effect of the MHS-10 monoclonal antibody (1:10 dilution) and null ascites ( $1: 10$ dilution), in the presence or absence of heparin, on sperm motility parameters was investigated using an HTM-2030 Motility Analyzer (Hamilton Thorn, Beverly, MA). Spermatozoa $\left(4 \times 10^{6}\right.$ spermatozoa $\mathrm{ml}^{-1}$ ) were incubated with heparin and antibodies in fertilization medium (devoid of oocytes) for $7 \mathrm{~h}$. Immediately before incubation and $7 \mathrm{~h}$ after incubation, $20 \mu \mathrm{l}$ aliquots of spermatozoa suspension were analysed for motility as described by Coonrod et al. (1994). The following sperm motility parameters were measured: motility (\%), progressive motility (\%) and progressive velocity $\left(\mu \mathrm{m} \mathrm{s}^{-1}\right.$ ) (Boyers et al., 1989).

\section{Spermatozoa viability and acrosomal status}

A dual-staining technique (Didion et al., 1989) using 0.4\% $(\mathrm{w} / \mathrm{v})$ trypan blue and $3 \%(\mathrm{w} / \mathrm{v})$ Giemsa was used to determine the viability and acrosomal status of spermatozoa in the treatment groups described in the sperm motility assay. Aliquots, $50 \mu \mathrm{l}$, of spermatozoa suspensions, were taken for assessment before the addition of antibodies and $6 \mathrm{~h}$ after treatment. The aliquots were mixed with an equal volume of $0.4 \%$ trypan blue in $\mathrm{PBS}$, and incubated at $37^{\circ} \mathrm{C}$ for $10 \mathrm{~min}$. Owing to the small quantities of spermatozoa used in this assay, removal of excess trypan blue by centrifugal washing was not possible. A washing technique was developed by placing the sperm suspension in a $10 \mathrm{ml}$ syringe containing $5 \mathrm{ml}$ PBS. The suspension was mixed well, filtered through a $0.2 \mathrm{~mm}$ Acrodisc filter (Gelman Sciences, Ann Arbor, MI), and flushed retrograde onto a microscope slide. The slides were then placed on a warming tray and air dried. A $3 \%(w / v)$ Giemsa stain solution was placed on the slides and incubated at room temperature for $1 \mathrm{~h}$. Excess stain was removed by washing with distilled water and the slides were covered with cover slips with Permount (Fischer Co., Chicago, Il). Stained sperm preparations were evaluated at $\times 400$ magnification with a bright field microscope. Because trypan blue specifically stains dead spermatozoa and Giemsa only stains the acrosome of spermatozoa which maintain an intact acrosomal matrix, it was possible to allot the spermatozoa into four groups: live and acrosome intact, live and acrosome reacted, dead and acrosome intact, and dead and acrosome reacted. 

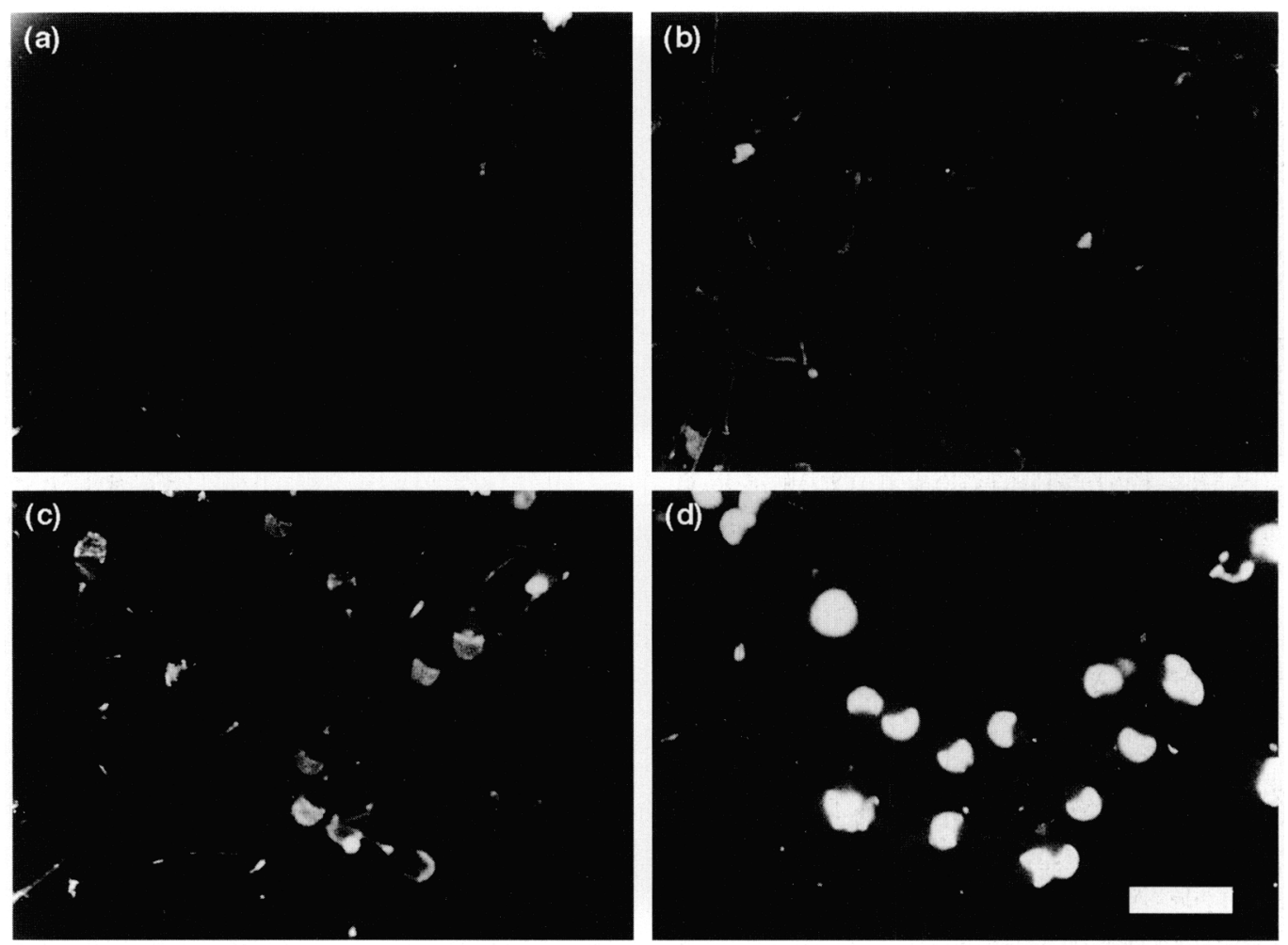

Fig. 1. Immunofluorescence patterns showing reactivity of SP-10 monoclonal antibodies (1:30 dilution) with methanol-fixed bovine spermatozoa. (a) The null ascites was not reactive with bovine spermatozoa. (b) The 3C12 monoclonal antibody reacted faintly with the apical region of the spermatozoa head and the tail of spermatozoa. (c) The 6C12 monoclonal antibody demonstrated moderate punctate to homogeneous immunofluorescence patterns over the acrosomal region. (d) The MHS-10 monoclonal antibody exhibited an intense acrosomal staining pattern. Scale bar represents $15 \mu \mathrm{m}$.

Statistical analyses

All quantitative data were subjected to least-squares analyses of variance using the General Linear Models procedures of the Statistical Analysis System (Spector et al., 1985). The statistical model included variation due to treatment. When significant effects were detected, individual means were compared using Duncan's New Multiple Range test. All quantitative data are expressed as least-squares means \pm SEM.

\section{Results}

\section{Immunofluorescence}

The three monoclonal antibodies to human SP-10 were tested separately for their reactivity with methanol-fixed bovine spermatozoa. The null ascites (Fig. Ia) were not reactive with spermatozoa while the $3 \mathrm{C} 12$ monoclonal antibody (Fig. 1b) showed faint reactivity to sperm tails and the apical region of the sperm head. The 6C12 monoclonal antibody demonstrated either moderate punctate or homogeneous staining over the acrosomal cap region (Fig. 1c), whereas the MHS-10 monoclonal antibody exhibited an intense fluorescent staining pattern over the acrosomal cap (Fig. Id).

The rabbit polyclonal antibody to human SP-10 (Fig. 2a) also reacted intensely with the acrosomal cap region of bovine spermatozoa as compared with the rabbit pre-immune sera (Fig. 2b). Acrosomal staining was not seen when the rabbit polyclonal antibody to human SP-10 was incubated with live spermatozoa (negative data not shown), thus indicating the absence of SP-10 on the plasma membrane of acrosome-intact bovine spermatozoa.

\section{Western blot analysis of bovine sperm proteins}

The three monoclonal antibodies to human SP-10 were used separately to identify and characterize immunoreactive SP-10 on western blots of sonicated extracts of frozen-thawed bovine spermatozoa. Under denaturing and reducing conditions, the MHS-10 mAb (Fig. 3, lane I) and 3C12 mAb (Fig. 3, lane 2) did not immunoreact with any bovine sperm proteins. The 6C12 monoclonal antibody (Fig. 3, lane 3) reacted strongly with three proteins in the $30-35 \mathrm{kDa}$ range and the null ascites (Fig. 3, lane 4) did not react strongly with any sperm proteins. Under native gel conditions, the MHS-10 mAb (Fig. 4, lane 1) and $6 \mathrm{C} 12 \mathrm{mAb}$ (Fig. 4, lane 3) reacted strongly with one protein at $37 \mathrm{kDa}$ and several fainter associated bands from 33 to $40 \mathrm{kDa}$. The $3 \mathrm{C} 12 \mathrm{mAb}$ (Fig. 4, lane 2) and the null ascites (Fig. 4, lane 4) did not recognize any sperm proteins.

Under denaturing and reducing conditions, the rabbit polyclonal antibody to human SP-10 (Fig. 5, lane 1) reacted strongly to bovine sperm proteins ranging from 18 to $35 \mathrm{kDa}$. 

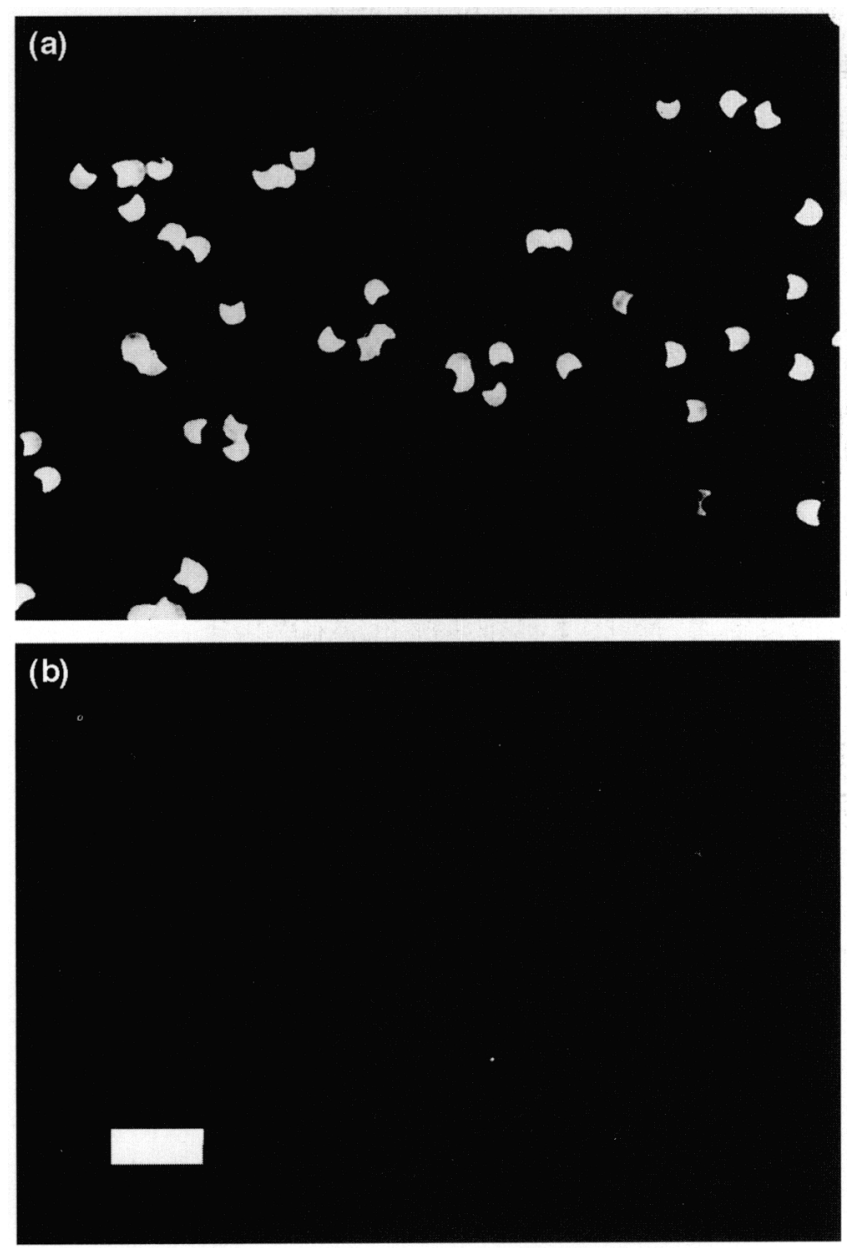

Fig. 2. Immunofluorescent/phase contrast photomicrographs showing reactivity of SP-10 polyclonal antibody (1:30 dilution) to methanolfixed bovine spermatozoa. (a) The SP-10 polyclonal antibody reacted strongly with the acrosomal region of spermatozoa. (b) The preimmune serum reacted weakly to the apical region of the spermatozoa head. Scale bar represents $20 \mu \mathrm{m}$.

Both the polyclonal antibody and the pre-immune sera (Fig. 5, lane 2) showed reactivity to several sperm proteins and these bands were considered non-specific. Under native gel conditions, a single broad band from 33 to $38 \mathrm{kDa}$ was recognized by the polyclonal antibody (Fig. 6, lane 1). Several protein bands ranging from 80 to $200 \mathrm{kDa}$ were faintly stained by both the polyclonal antibody and the pre-immune sera (Fig. 6, lane 2) and were considered non-specific.

\section{Inhibitory effect of monoclonal antibodies to SP-10 on bovine IVF}

The effect of a cocktail of MHS-10, 3C12 and 6C12 monoclonal antibodies on bovine IVF was tested using 635 oocytes in four separate trials. There was no difference $(P>0.10)$ in the fertilization rate of the control group lacking antibodies $(86.5 \%)$ when compared with either the group receiving a $1: 10$ dilution of null ascites $(83.2 \%)$ or the group treated with a 1:40 dilution of SP-10 monoclonal antibodies $(86.0 \%)$. However, the fertilization rates were significantly lower $(P<0.01)$ at dilutions of $1: 20(47.7 \%)$ and $1: 10(7.5 \%)$

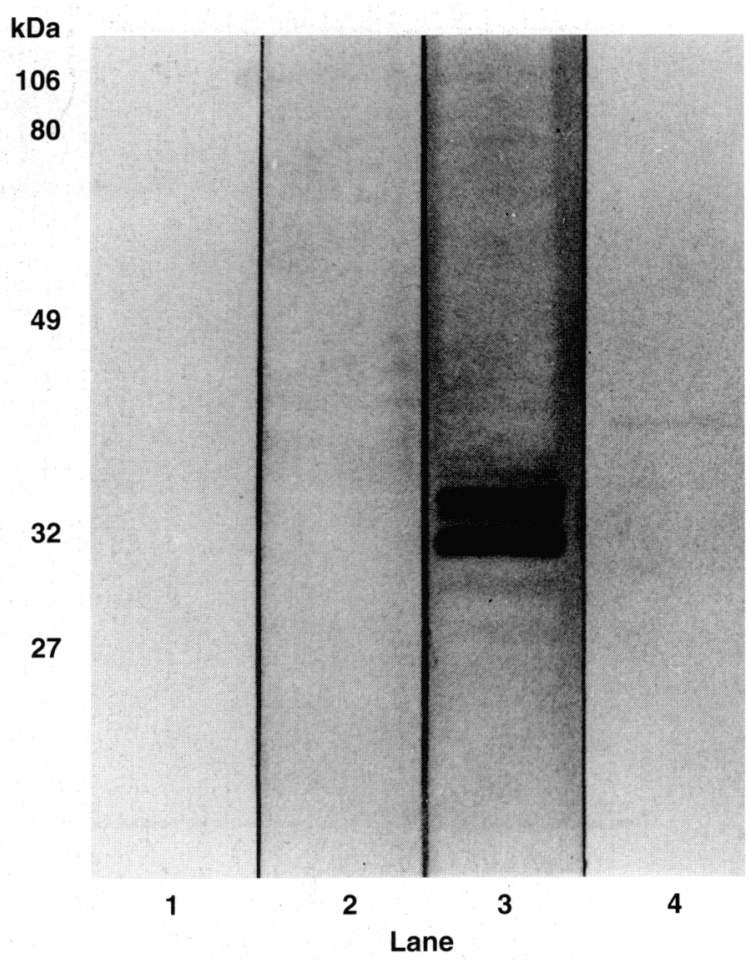

Fig. 3. Western blot of SP-10 monoclonal antibody reactivity with sonicated bovine spermatozoa extracts under denaturing and reducing electrophoretic conditions. Lanes were loaded with $50 \mu \mathrm{g}$ protein and extracts were incubated with 1:100 dilutions of SP-10 monoclonal antibodies or null ascites. Lane I: MHS-10 monoclonal antibody. Lane 2: 3C12 monoclonal antibody. Lane 3: 6C12 monoclonal antibody. Lane 4: null ascites.

than those of the control group and the group treated with SP-10 monoclonal antibodies at a 1:40 dilution. The observation that the percentage of eggs penetrated by spermatozoa was significantly less $(P<0.01)$ at a $1: 10$ dilution than at a $1: 20$ dilution of the SP-10 monoclonal antibodies demonstrates a dose-dependent effect of monoclonal antibodies to SP-10 on bovine fertilization rates.

Effect of absorption with recombinant SP-10 on fertilization rates mediated by MHS-10 monoclonal antibody

Of the three monoclonal antibodies used in the immunofluorescence experiments, MHS-10 gave the strongest reactivity with bovine SP-10. The effect of the MHS-10 monoclonal antibody alone was therefore tested using 430 oocytes in three trials. To validate that possible reductions in fertilization rates were due to MHS-10 and not to another component of the ascites, $100 \mu \mathrm{g}$ rbSP-10 was used to absorb MHS-10 antibody from the ascites. This quantity of rbSP-10 was chosen because it demonstrated the maximum absorption of MHS-10 monoclonal antibody from the ascites. The fertilization rates between absorbed and unabsorbed MHS-10 monoclonal antibody ascites were then compared. The fertilization rate was significantly reduced $(P<0.01)$ to $16 \%$ in the group treated with a 1:10 dilution of unabsorbed MHS-10 monoclonal antibody ascites. There was no difference $(P<0.10)$ in the fertilization 


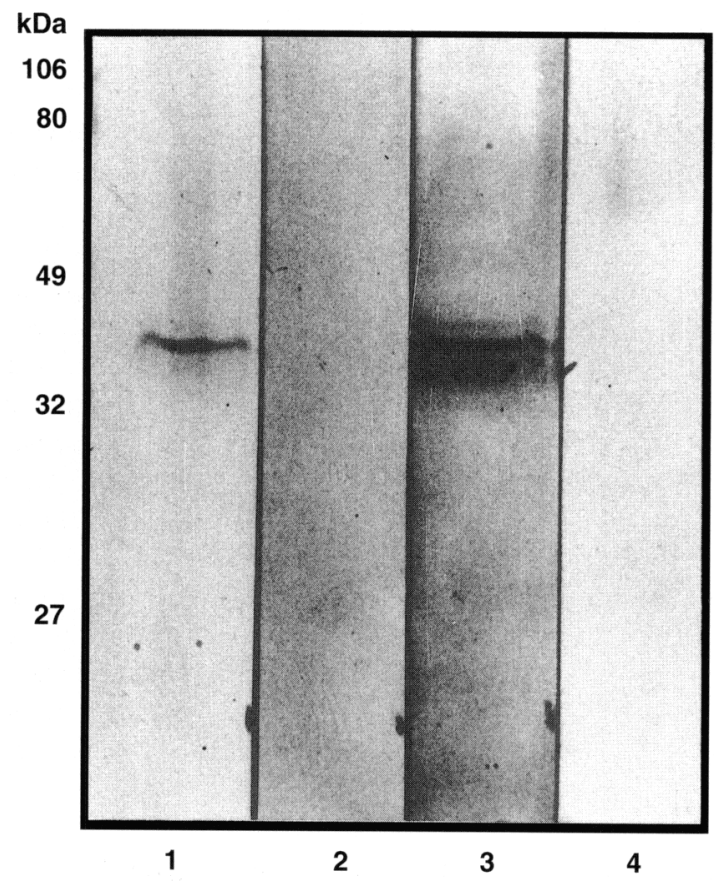

Fig. 4. Western blot of SP-10 monoclonal antibody reactivity with sonicated bovine sperm extracts under non-denaturing and nonreducing electrophoretic conditions. Lanes were loaded with $50 \mu \mathrm{g}$ protein and extracts were incubated with 1:100 dilutions of SP-10 monoclonal antibodies or null ascites. Lane I: MHS-10 monoclonal antibody. Lane 2: 3C12 monoclonal antibody. Lane 3: 6C12 monoclonal antibody. Lane 4: null ascites.

rates between the control lacking antibodies (85.3\%), a 1:10 dilution of null ascites $(87.6 \%)$ and a 1:10 dilution of MHS-10 ascites absorbed with rbSP-10 (81.3\%).

\section{Effect of polyclonal antibodies to human SP-10 on bovine IVF}

A total of 465 oocytes were used in three separate trials to test the effects of the rabbit polyclonal antibodies of human SP-10 on bovine IVF. There was no significant difference $(P>0.10)$ in the fertilization rates between the control lacking antibodies $(79 \%)$, a 1:10 dilution of pre-immune sera $(84 \%)$, and the SP-10 polyclonal antibodies at dilutions of 1:40 (77.0\%) and 1:20 $(69.0 \%)$. There was a significant reduction $(P<0.01)$ in the fertilization rate at a 1:10 dilution of SP-10 polyclonal antibodies $(44.3 \%)$.

\section{Sperm-zona binding}

Qualitative observations. The number of spermatozoa bound to each oocyte $17 \mathrm{~h}$ after fertilization was investigated to determine the effect of the SP-10 monoclonal antibody cocktail on sperm-zona binding. Two hundred and forty oocytes in three separate trials were scored in this experiment. Both the null ascites (1:10 dilution) and the SP-10 monoclonal antibody (1:10 dilution) treatment groups had 100 or more spermatozoa bound to the zona before pipetting. However, a difference was noted in the depth of zona penetration in the two groups. Spermatozoa in the null ascites group were either

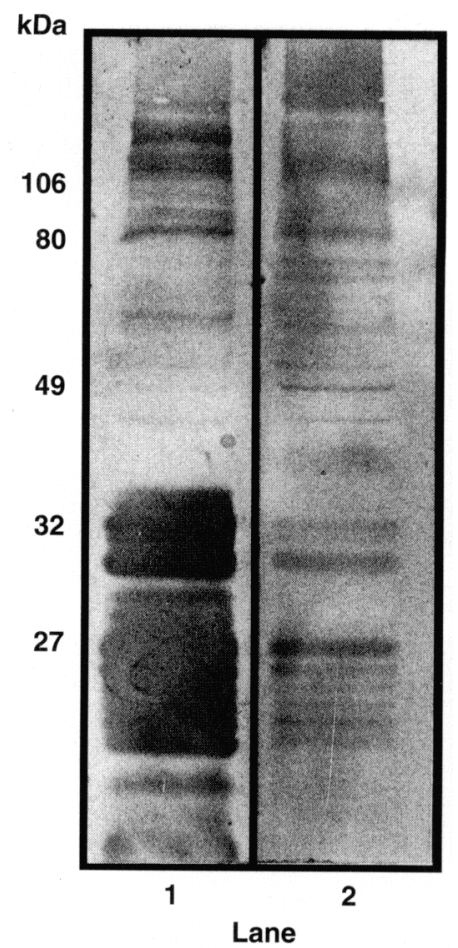

Fig. 5. Western blot demonstrating reactivity of polyclonal antibodies to human SP-10 with sonicated bovine spermatozoa extracts under denaturing and reducing electrophoretic conditions. The rabbit polyclonal antibody was generated against recombinant baboon SP-10. Lanes were loaded with $50 \mu \mathrm{g}$ protein and extracts were incubated with 1:100 dilutions of SP-10 polyclonal antibodies or pre-immune sera. Lane 1: SP-10 polyclonal antibody. Lane 2: pre-immune sera.

tangentially bound to, or partially buried in, the zona, whereas spermatozoa in the SP-10 monoclonal antibody group were only peripherally associated with the zona pellucida.

Quantitative observations. After pipetting five times to remove loosely bound spermatozoa, eggs were scored for bound spermatozoa. Each zona in the null ascites group had an average of 35.1 spermatozoa bound, which was significantly more $(P<0.05)$ than the 3.0 spermatozoa bound in the SP-10 monoclonal antibody group. After eggs were vortexed for $3 \mathrm{~min}$, the null ascites group averaged 4.9 spermatozoa per oocyte (either tightly bound to the zona or in the perivitelline space) which was significantly greater $(P<0.05)$ than the 0.37 spermatozoa in the group treated with SP-10 monoclonal antibody. Representative photomicrographs for null ascites before pipetting (a), SP-IO monoclonal antibody before pipetting (b), null ascites after pipetting (c) and SP-10 monoclonal antibody after pipetting (d) are shown (Fig. 7). The data are summarized in Table 1.

\section{Parameters of sperm motility}

Qualitative observations. Two hours after incubation with heparin, spermatozoa treated with the MHS-10 monoclonal antibody and the null ascites underwent head-to-head 


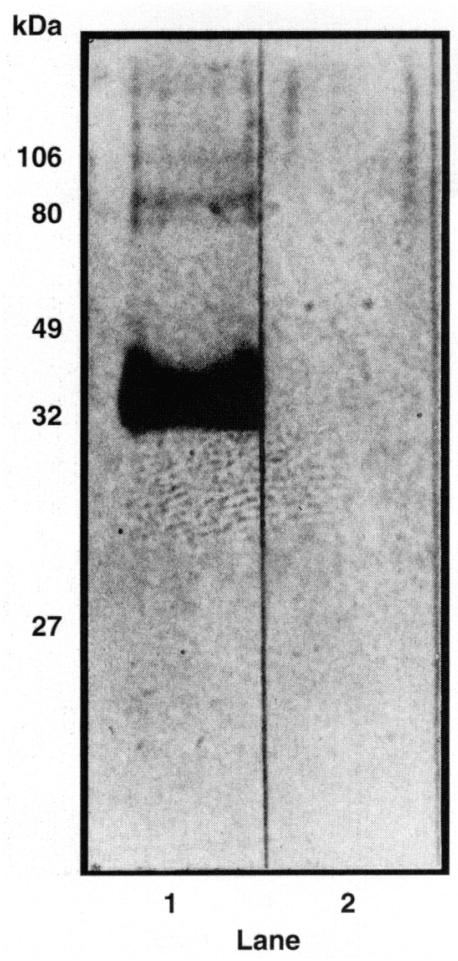

Fig. 6. Western blot demonstrating reactivity of polyclonal antibodies to human SP-10 with sonicated bovine spermatozoa extracts under non-denaturing non-reducing electrophoretic conditions. The polyclonal antibody was generated against recombinant baboon SP-10. Lanes were loaded with $50 \mu \mathrm{g}$ protein and extracts were incubated with 1:100 dilutions of SP-10 polyclonal antibodies or pre-immune sera. Lane 1: SP-10 polyclonal antibody. Lane 2: pre-immune sera.

agglutination with their tails beating actively. One to two hours later, the spermatozoa in both groups had dispersed and had begun to swim freely. In the null ascites group, shortly after dispersion approximately $25 \%$ of the spermatozoa began to display a motility pattern characterized by reduced forward motility and extreme tail flagellations. Spermatozoa in the MHS-10 monoclonal antibody group remained motile for about $\mathrm{Ih}$ after dispersion and then began to settle to the bottom of the dish. While most of these spermatozoa did not exhibit progressive motility, they maintained weak head and tail flagellations. In the MHS-10 monoclonal antibody and null ascites treatment groups without heparin, sperm agglutination was not observed and motility characteristics were not different from each other.

Quantitative observations. At least 100 spermatozoa per treatment in each of four separate trials were studied in a Hamilton Thorn Motility Analyzer. The percentage motility, percentage rapid motility, and progressive velocity $\left(\mu \mathrm{m} \mathrm{s}^{-1}\right)$ of spermatozoa were evaluated before and $7 \mathrm{~h}$ after treatment. The experimental groups were: (1) treated with neither heparin nor antibody and evaluated initially, (2) treated with MHS-10 monoclonal antibody (1:10 dilution) and heparin, (3) treated with MHS-10 monoclonal antibody (1:10 dilution) without heparin, (4) treated with null ascites (1:10 dilution) and heparin, or (5) treated with null ascites (1:10 dilution) without heparin (Fig. 8).
The motility and rapid motility of spermatozoa was significantly higher $(P<0.01)$ in the preparation examined before treatment than in all groups $7 \mathrm{~h}$ after treatment. After treatment for $7 \mathrm{~h}$ the motility and rapid motility of spermatozoa from the MHS-10 monoclonal antibody group with heparin was significantly lower $(P<0.01)$ than in spermatozoa from all other groups, including the group treated with heparin.

The progressive velocity of spermatozoa was significantly lower $(P<0.01)$ in the group treated with the MHS-10 monoclonal antibody and heparin compared with the group evaluated initially. After $7 \mathrm{~h}$ treatment, the progressive velocity of the group treated with the MHS-10 monoclonal antibody and heparin was not different $(P>0.10)$ to that of the group treated with null ascites and heparin but was significantly lower than in all other groups $(P<0.01)$.

Thus, in the presence of heparin, an agent which induces the acrosome reaction, the MHS-10 mAb had significantly reduced the percentage motility and percentage rapid motility, while not affecting the progressive velocity of spermatozoa. In the absence of heparin, the MHS-10 mAb had no effect on the motility parameters of the spermatozoa.

\section{Viability and acrosomal status of spermatozoa treated with MHS-10 $m A b$}

The viability and acrosomal status of spermatozoa were investigated in the treatment groups noted above. At least 100 spermatozoa per treatment group, in each of four separate trials, were evaluated by dual staining in randomly selected fields. Spermatozoa were categorized as: (1) live and acrosome intact, (2) live and acrosome reacted, (3) dead and acrosome intact and (4) dead and acrosome reacted.

Viability. There were no significant differences $(P>0.10)$ in the percentage of dead spermatozoa (Fig. 9) in any group. In particular it should be noted that the MHS-10 monoclonal antibody had no effect on the viability of bovine spermatozoa.

Acrosomal status. The percentage of acrosome-reacted spermatozoa in the null ascites group treated with heparin was significantly higher $(P<0.01)$ than in all other groups (Fig. 9). The null ascites group without heparin and the MHS-10 monoclonal antibody groups (either with or without heparin) showed no difference $(P>0.10)$ in the percentage of acrosomereacted spermatozoa. These results indicate that although heparin is capable of increasing the percentage of spermatozoa undergoing the acrosome reaction (Handrow et al., 1982), the ability of spermatozoa to complete the acrosome reaction was reduced in the presence of the MHS-10 monoclonal antibody.

\section{Discussion}

Immunofluorescent microscopy revealed that the MHS-10 monoclonal antibody, 6C12 monoclonal antibody, and polyclonal antibody to human SP-10 react with native SP-10 present in bovine spermatozoa. The localization of bovine SP-10 to the acrosomal cap of methanol-fixed, but not live, spermatozoa confirms previous results in other species as to the presence of SP-10 within the acrosome (Foster and Herr, 1992). 

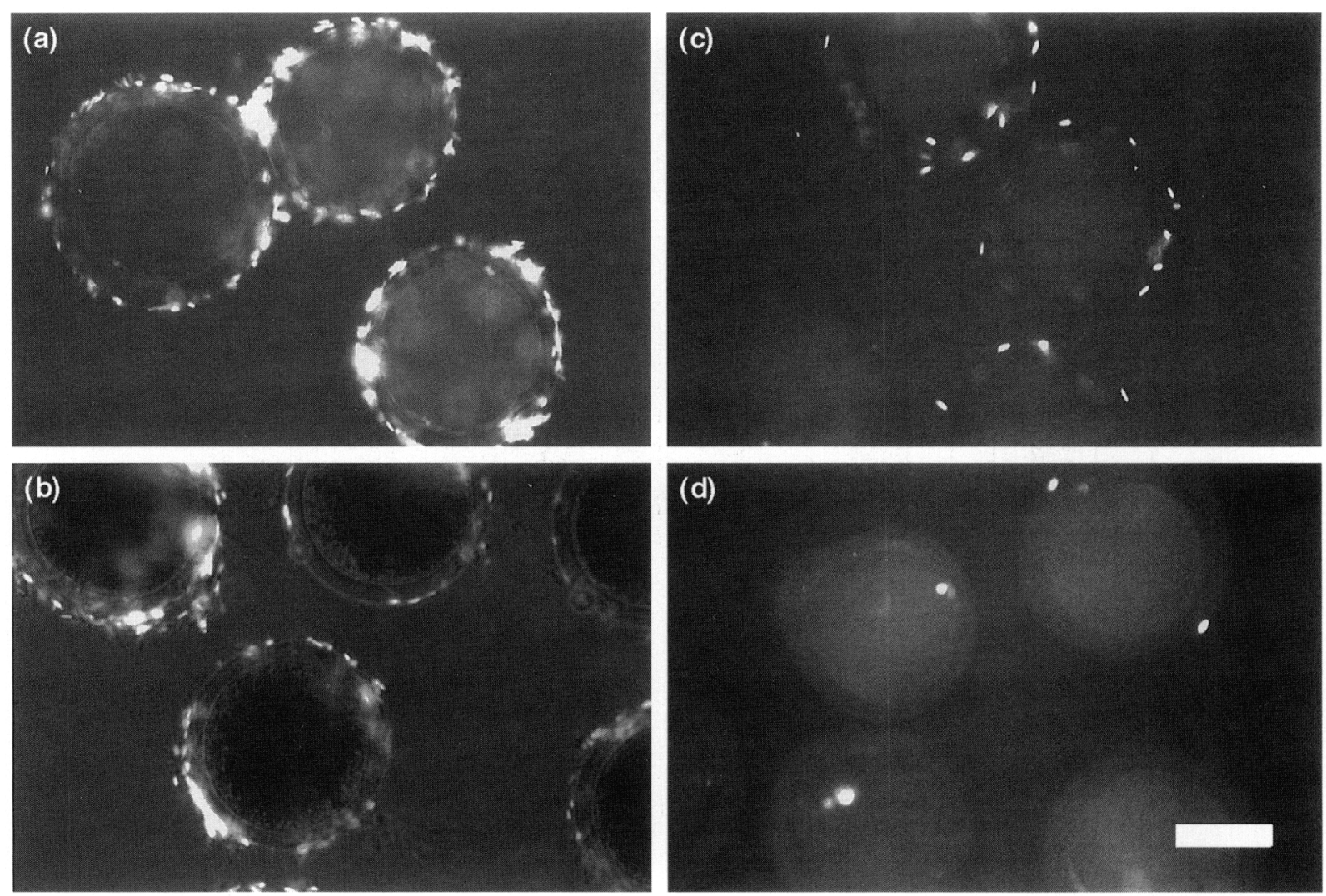

Fig. 7. Effect of SP-10 monoclonal antibody cocktail on bovine sperm-zona binding. Representative photomicrographs showing the number of spermatozoa bound to each oocyte after $17 \mathrm{~h}$ co-culture. (a) . Vull ascites before pipetting. (b) SP-10 monoclonal antibody before pipetting. (c) Null ascites after pipetting. (d) SP-10 monoclonal antibody after pipetting. Scale bar represents $50 \mu \mathrm{m}$.

Table 1. Effect of SP-10 mAb cocktail on bovine sperm-zona binding*

Number of sperm bound per oocyte Is h after fertilization

Betore After After

Antibody pipetting pipettingt vortexing ${ }^{*}$

\begin{tabular}{|c|c|c|c|}
\hline $\begin{array}{c}\text { Null ascites } \\
(1: 10)\end{array}$ & $>100$ & $35.0^{\circ}$ & $4.9^{1}$ \\
\hline $\begin{array}{l}\text { SP } 10 \mathrm{mAb} \text { cocktail } \\
(1: 10)\end{array}$ & $>100$ & $3.0^{b}$ & $0.37^{\circ}$ \\
\hline
\end{tabular}

*Tight binding assay described in Materials and Metheds.

tResults represent the least-syuares moans from four replicates with ten oocyles being cvaluated per group per replicale.

" Values followed by different letters are significantls different $1 !<0.05$ $1: 1:=1.81$.

The observation that peptides in extracts of bovine spermatozoa were immunoreactive with previously characterized SP-10 specific monoclonal and polyclonal antibodies on immunoblots, and that the immunoreactive peptides were of a similar molecular mass to human SP-10 demonstrates the presence of SP-10 in bovine spermatozoa. The fact that the 6C12 monodonal antibody recognized multiple reduced protein bands suggests that bovine SP-10 has similar microheterogencity as has been demonstrated in human and non-human primate spermatozoa (Herr et al., 1992).

Treatment with the SP-IO monoclonal antibody cocktail resulted in a dose-dependent decrease in fertilization rates, with significant reductions seen at dilutions of $1: 20$ and $1: 10$. Significant anti-fertilization effects were also observed after treatment with a $1: 10$ dilution of the MHS-10 monoclonal antibody alone. Specificity of the anti-fertilization effect of the MHS-10 monoclonal antibody was determined by elimination of the effect by absorption: fertilization rates were not different from controls when the MHS-10 monoclonal antibody was absorbed from the fertilization medium using rbSP-10. Furthermore, fertilization rates were also significantly reduced using a L:I0 dilution of polyclonal antisera to SP-JO.

While previous investigations have demonstrated that antibodies to SP-io reduce fertilization rates in vitro (Anderson et al., 1987; Dubova-Mihailova et al., 1991), it is not clear at what point in the fertilization process the antibodies exert their effect. However, the intra-acrosomal localization of SP-10 led previous investigators to speculate that antibodies to SP-10 would have no effect on the primary binding of spermatozoa to zona, but could reduce fertilization rates by preventing SP-10 from functioning in the acrosome reaction, in the tight binding of spermatozoa to zona following exposure of the acrosomal compartment to the extraccllular fluid, or in both processes (Foster ef al., 1994). 


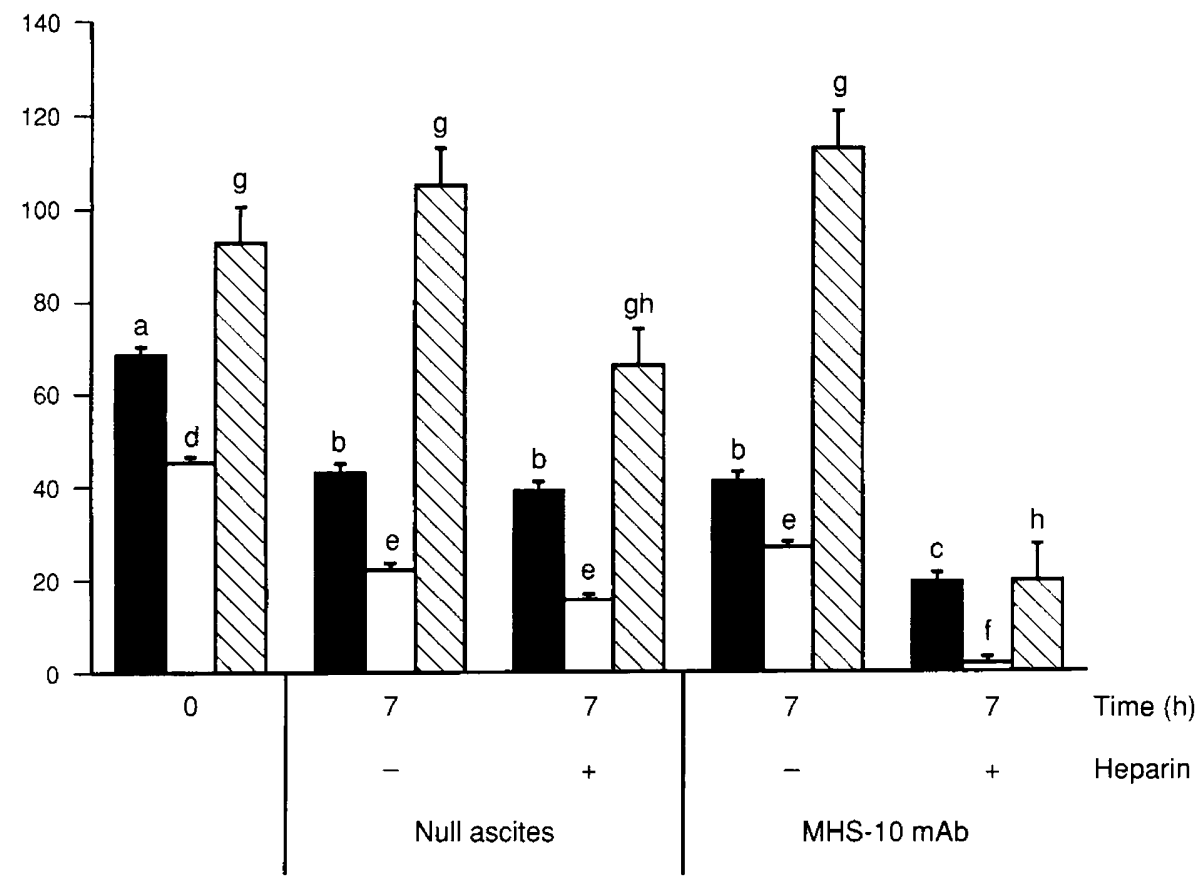

Fig. 8. Effect of MHS-10 monoclonal antibody (in the presence or absence of $10 \mu \mathrm{g}$ heparin $\mathrm{ml}^{-1}$ ) on the motility parameters of bovine spermatozoa. The $(\square)$ motility $(\%),(\square)$ rapid motility (\%), and $(\mathbb{\nabla})$ progressive velocity $\left(\mu \mathrm{m} \mathrm{s}^{-1}\right.$ ) were evaluated using a computerized motility analyser. Motility parameters were evaluated before treatment and after incubation for $7 \mathrm{~h}$. Values are least-squares means from four replicates. Within each motility parameter, different letters represent significant differences $(P<0.01)$. The SEMS for motility, rapid motility and progressive velocity are $1.8,1.3$ and 7.7 , respectively.

Results from the current study confirm this hypothesis. The sperm-zona binding assay demonstrated that both the SP-10 monoclonal antibody and null ascites group had in excess of 100 spermatozoa bound per zona pellucida before pipetting; therefore, SP-10 antibodies do not reduce sperm-zona primary binding. However, after removal of loosely bound spermatozoa, there was a significant reduction in the number of tightly bound spermatozoa in the SP-10 monoclonal antibody group when compared with the null ascites group, thus confirming the inhibitory effect of SP-10 antibodies on the tight binding, of spermatozoa to zona.

The present study also reveals a possible mechanism of action by which antibodies to SP-10 prevent sperm-zona tight binding. The acrosomal status of spermatozoa was evaluated using Giemsa stain, which tests for the presence of an intact acrosomal matrix (Saacke and Marshall, 1968). Results from the acrosomal status assay demonstrate that, under capacitating conditions, there were significantly more spermatozoa maintaining intact acrosomal matrices in the group incubated with SP-10 antibodies when compared with the null ascites group. Therefore, antibodies to SP-10 reduced the efficiency of acrosomal matrix loss during the spontaneous acrosome reaction.

Anti-SP-10 antibodies could gain access to the SP-10 protein at some point in time between fusion pore formation (possibly during hydration of the acrosomal matrix) and loss of the acrosomal matrix. If SP-10 antibodies enter the acrosomal compartment through fusion pores during hydration of the acrosomal matrix and bind to SP-10, it is possible that the acrosome reaction would be halted before membrane vesiculation, with the plasma membrane remaining mostly intact. Alternatively, SP-10 antibodies could bind to SP-10 after membrane vesicle formation and before dispersal of the acrosomal matrix. In either case, these spermatozoa would be unable to undergo tight binding because the secondary binding proteins of the inner acrosomal membrane would be sterically prevented from interacting with the zona pellucida.

Antibody binding to SP-10 may directly inhibit SP-10 function, or completion of the acrosome reaction may be prevented by steric effects of cross-linking SP-10 as the acrosomal matrix hydrates. Because completion of the acrosome reaction and suppressed motility were observed in heparin-capacitated spermatozoa treated with SP-10 antibodies, it is possible that dispersal of the acrosomal contents is necessary to maintain sperm motility after the acrosome reaction has occurred.

Morphological studies are underway to test the hypothesis that SP-10 antibodies effect fertilization by binding to SP-10 and preventing dispersal of the acrosomal matrix. Electron microscopy will be used to investigate the ultrastructure of spermatozoa treated with SP-10 antibodies as they undergo a solubilized zona pellucida-induced acrosome reaction. If the prediction that SP-10 antibodies prevent dispersal of the acrosomal matrix is correct, then spermatozoa treated with SP-10 antibodies and induced to acrosome react should remain arrested at some point between fusion pore formation and loss of the acrosomal matrix. Also SP-10 antibodies should be found associated with the acrosomal matrix in these spermatozoa. 


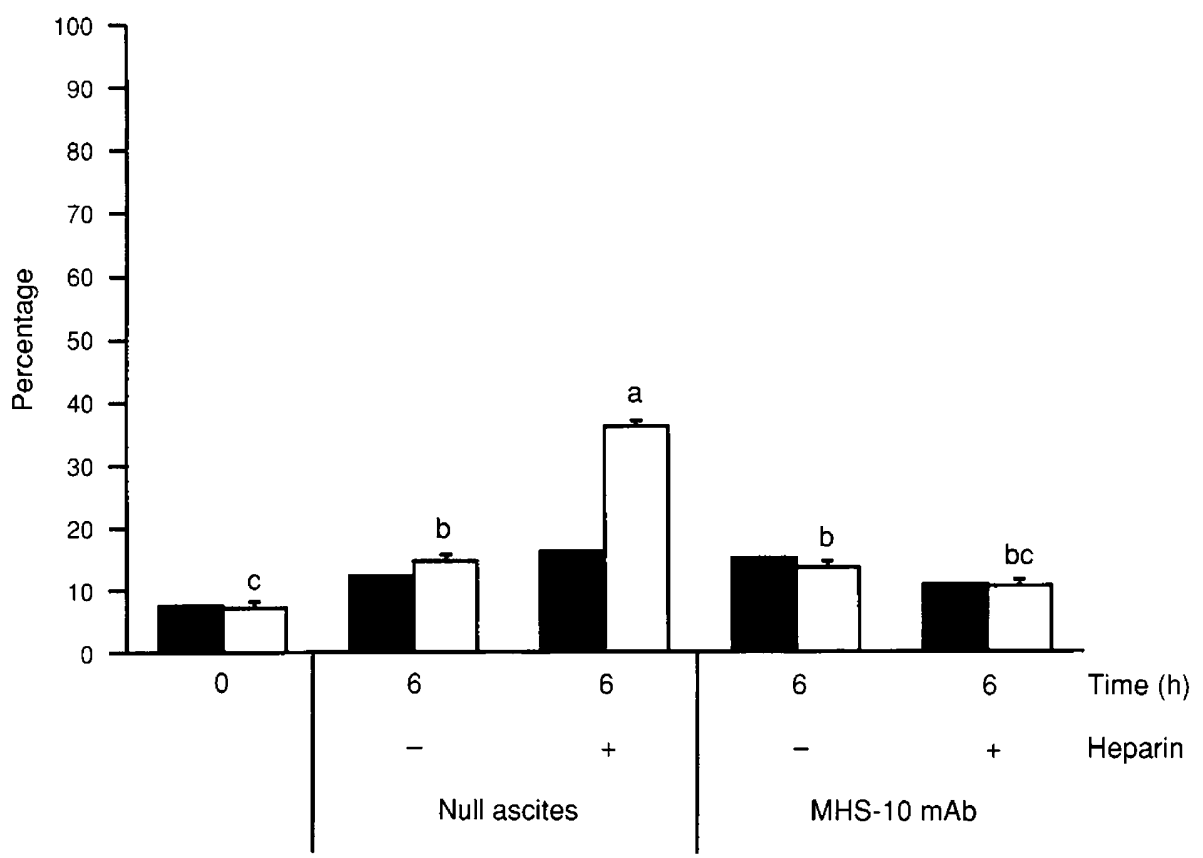

Fig. 9. Effect of MHS-10 monoclonal antibody (in the presence or absence of $10 \mu \mathrm{g}$ heparin $\mathrm{ml}^{-1}$ ) on the percentage of ( $)$ dead and $(\square)$ acrosome-reacted spermatozoa. Spermatozoa were evaluated before treatment and after $6 \mathrm{~h}$ incubation. Within each parameter different letters represent significant differences $(P<0.01)$. Values are least-squares means from four repetitions. The SEMS for the percentage dead spermatozoa and percentage acrosome-reacted spermatozoa are 1.2 and 0.61 , respectively.

The authors thank T. Ott, T. Spencer and all other individuals associated with the Center for Animal Biotechnology, Texas A\&M University (College Station, TX) for their excellent technical assistance. This work was supported by NIH P 30-28934, a grant from the Andrew W. Mellon Foundation, and CSA-93-125 from the CONRAD program of USAID.

\section{References}

Anderson DJ, Johnson PM, Alexander NJ, Jones WR and Griffin PD (1987) Monoclonal antibodies to human trophoblast and spermatozoa antigens: report of two WHO-sponsored workshops Journal of Reproductive Immunology 10 231-257

Boyers SP, Davis RO and Katz DF (1989) Automated semen analysis. In Current Problems in Obstetrics and Gynecology and Fertility pp 167-200 Ed. RL Barbieri. Year Book Medical Publishers, New York

Bradford MM (1976) A rapid and sensitive method for the quantitation of microgram quantities of protein utilizing the principle of protein-dye binding Analytical Biochemistry 72 248-254

Chapman MD, Sutherland WM and Plats-Mills TE (1984) Recognition of two dermatophagoides pteronyssinus-specific epitopes on antigen P1 by using monoclonal antibodies: binding to each epitope can be inhibited by serum from dust mite-allergic patients Journal of Immunology 133 2488-2495

Coonrod SC, Westhusin ME and Naz RK (1994) Monoclonal antibody to human fertilization antigen-I (FA-1) inhibits bovine fertilization in vitro: application in immunocontraception Biology of Reproduction 51 14-23

Didion BA, Dobrinsky JR, Giles JR and Graves CN (1989) Staining procedure to detect viability and the true acrosome reaction in spermatozoa of various species Gamete Research 22 51-57

Dubova-Mihailova M, Mollova M, Ivanova M, Kehayov and Kyurkchiev S (1991) Identification and characterization of human acrosomal antigen defined by a monoclonal antibody with blocking effect on in vitro fertilization Journal of Reproductive Immunology 19 251-268

Foster JA and Herr JC (1992) Interactions of human sperm acrosomal protein SP-10 with the acrosomal membranes Biology of Reproduction $46981-990$
Foster JA, Klotz K, Flickinger CJ, Thomas TS, Wright RM, Castillo JR and Herr JC (1994) Human SP-10: acrosomal distribution, processing, and fate after the acrosome reaction Biology of Reproduction $\mathbf{5 1} 1222-1231$

Freemerman AL, Wright RM, Flickinger CJ and Herr JC (1994) Tissue specificity of the acrosomal protein SP-10: a contraceptive vaccine molecule Biology of Reproduction 50 615-621

Handrow RR, Lenz RW and Ax RL (1982) Structural comparisons among glycosaminoglycans to promote an acrosome reaction in bovine spermatozoa Biochemical and Biophysical Research Communications 107 1326-1332

Handrow RR, Parrish JJ and Susko-Parrish JL (1986) Effect of glycosaminoglycans on capacitation and the acrosome reaction of bovine and hamster sperm Biology of Reproduction 34 (Supplement) 93

Herr JC, Wright RM, John E, Foster J, Kays T and Flickinger C (1990a) Identification of human acrosomal antigen SP-10 in primates and pigs Biology of Reproduction 42 377-382

Herr JC, Flickinger CJ, Homyk M, Klotz K and John E (1990b) Biochemical and morphological characterization of the intra-acrosomal antigen SP-10 from human sperm Biology of Reproduction 42 181-193

Herr JC, Klotz K, Shannon J, Wright RM and Flickinger CJ (1992) Purification and microsequencing of the intra-acrosomal protein SP-10. Evidence that SP-10 heterogeneity results from endoproteolytic processes Biology of Reproduction 47 11-20

Herr JC, Wright RM, Klotz K, Homyk M, Kornreich B, Flickinger CJ, Powell J and Stevens V (1994) Immunogenicity of SP-10 fusion proteins in female baboons. In Recombinant and Synthetic Vaccines pp 239-251 Ed. GP Talwar. Narosa Publishing, New Delhi

Hudson L and Hay FC (1983) Practical Immunology pp 101-124. Blackwell Scientific, New York

Jimenez C, Benoit S, Genevieve G, Artonne C, Kemeny JL and Boucher D (1994) Characterization of a monoclonal antibody to an intra-acrosomal antigen that inhibits fertilization Biology of Reproduction 51 1117-1125

Kurth BE, Klotz K, Flickinger CJ and Herr JC (1991) Localization of sperm antigen SP-10 during the six stages of the cycle of seminiferous epithelium in man Biology of Reproduction 44 814-821

Laemmli UK (1970) Cleavage of structural proteins during the assembly of the head of bacteriophage T4 Nature 220 680-685 
Lenz RW, Bellin ME and Ax RL (1983) Rabbit spermatozoa undergo an acrosome reaction in the presence of glycosaminoglycans Gamete Research $\mathbf{8}$ 11-19

Naz RK, Ahmad K and Kumar G (1991) Presence and role of c-myc protooncogene in mammalian sperm cell function Biology of Reproduction 44 $842-850$

Parish JJ, Susko-Parrish J, Winer MA and First NL (1988) Capacitation of bovine sperm by heparin Biology of Reproduction 38 1171-1180

Reddi PP, Castillo JR, Klotz K, Flickinger CJ and Herr JC (1994) Production in Escherichia coli, purification and immunogenicity of acrosomal protein SP-10, a candidate contraceptive vaccine Gene 147 189-195

Reddi PP, Hansen SN, Aguolnik I, Tsai JY, Silver LM, Flickinger CJ and Herr JC (1995) Complementary deoxyribonucleic acid cloning and characterization of mSP-10: the mouse homologue of human acrosomal protein SP-10 Biology of Reproduction 53 873-881
Saacke RG and Marshall CE (1968) Observations on the acrosomal cap of fixed and unfixed bovine spermatozoa Journal of Reproduction and Fertility 16 511-514

Spector PC, Goodnight JH, Sall JP and Sarle WS (1985) The GLM procedures SAS User's Guide Statistics Version 5 pp 443. SAS Institute, Cary, NC

Towbin H, Stachelin T and Gordon J (1979) Electrophoretic transfer of proteins from poly-acrylamide gels to nitrocellulose sheets Proceedings of the National Academy of Sciences USA 76 4350-4354

Westhusin M, Moreno JF, DeAzambuja RM and Kraemer DC (1992) Transport and maturation of bovine oocytes in a non- $\mathrm{CO}_{2}$ environment Biology of Reproduction 48 (Supplement 1) 169

Wright RM, John E, Klotz K, Flickinger CJ and Herr JC (1990) Cloning and sequencing of cDNAs coding for the human intra-acrosomal antigen SP-10 Biology of Reproduction 42 693-701 